\title{
Adult adipose-derived stem cells and breast cancer: a controversial relationship
}

\author{
Alessandra Bielli ${ }^{1}$, Maria Giovanna Scioli ${ }^{1}$, Pietro Gentile ${ }^{2}$, Sara Agostinelli ${ }^{1}$, Chiara Tarquini ${ }^{1}$, Valerio Cervelli ${ }^{2}$ \\ and Augusto Orlandi ${ }^{*}$
}

\begin{abstract}
Breast cancer is the most common cancer in women and autologous fat grafting is an important clinical application in treatment of post-surgical deformities. The simplicity of fat grafting procedures and the absence of subsequent visible scar prompted an increasing interest for this technique. The plasticity of adipose-derived stem cells (ASCs) obtained from stromal vascular fraction (SVF) of adult adipose tissue provided exciting perspectives for regenerative medicine and surgery. The recent discovery that SVF/ASC enrichment further ameliorates clinical efficacy of grafting ASCs suggest as ASC-mediated new adipogenesis and vasculogenesis. ASC adipogenic differentiation involves Akt activity and EGFRs, FGFRs, ERbB2 receptor-mediated pathways that also play a pivotal role in the regulation of breast cancer growth. Moreover, the finding that platelet-derived growth factors and hormones improved long-term maintenance of fat grafting raises new concerns for their use during breast reconstruction after cancer surgery. However, it remains unclear whether grafted or resident ASCs may increase the risk of de novo cancer development or recurrence. Preliminary follow-up studies seem to support the efficacy and safety of SVF/ASCs enrichment and the additional benefit from the combined use of autologous platelet-derived growth factors and hormones during breast reconstruction procedures. In the present review we highlighted the complex interplay between resident or grafted ASCs, mature adipocytes, dormant or active breast cancer cells and tumor microenvironment. Actually, data concerning the permissive role of ASCs on breast cancer progression are contrasting, although no clear evidence speaking against their use exists.
\end{abstract}

Keywords: Adipose-derived stem cell; Stromal vascular fraction; Fat grafting; Breast cancer; Carcinogenesis; Breast reconstruction; Akt

\section{Introduction}

Adult adipose tissue is a multifunctional organ that contains various cellular types, including mature adipocytes, macrophages and stromal cells, supported by connective tissue surrounding fine capillaries (Zuk et al. 2001; Gentile et al. 2012a; Tran et al. 2012). When isolated in vitro, stromal cells have the potential to form bone, cartilage, muscle and fat tissues and have been variously termed, including preadipocytes and multipotent adipose-derived stem cells. However, the term "adipose-derived stem cells" (ASCs) has been successively recommended for the consistency between research groups (Zhao et al. 2010). In adult adipose tissue (Figure 1A), ASCs are considered to reside between mature adipocytes and extracellular matrix around

\footnotetext{
* Correspondence: orlandi@uniroma2.it

${ }^{1}$ Anatomic Pathology, Tor Vergata University of Rome, Via Montpellier, 00133 Rome, Italy

Full list of author information is available at the end of the article
}

small vessels (Tran et al. 2012). In fact, transmission electron microscopy of human breast adipose tissue showed the presence of cells featuring ASCs arranged around the endothelial cells of small vessels (Figure 1B), strongly supporting their perivascular origin (Traktuev et al. 2008; Crisan et al. 2008). ASCs likely contribute to adipose tissue cell turn-over (Strawford et al. 2004; Wang et al. 2012a). ASCs can be isolated from subcutaneous adult adipose tissue after liposuction by enzymatic digestion (Gimble et al. 2007; Cervelli et al. 2009). After centrifugation, the obtained heterogeneous mixture of endothelial cells, smooth muscle cells, fibroblast, pericytes, mast cells and preadipocytes is named stromal-vascular fraction (SVF). ASCs can be separated from SVF by adhesion on plastic dishes (Gimble et al. 2007; Cervelli et al. 2009). Before discovering of the plasticity of ASCs, bone marrow was clinically considered the major tissue source of human 


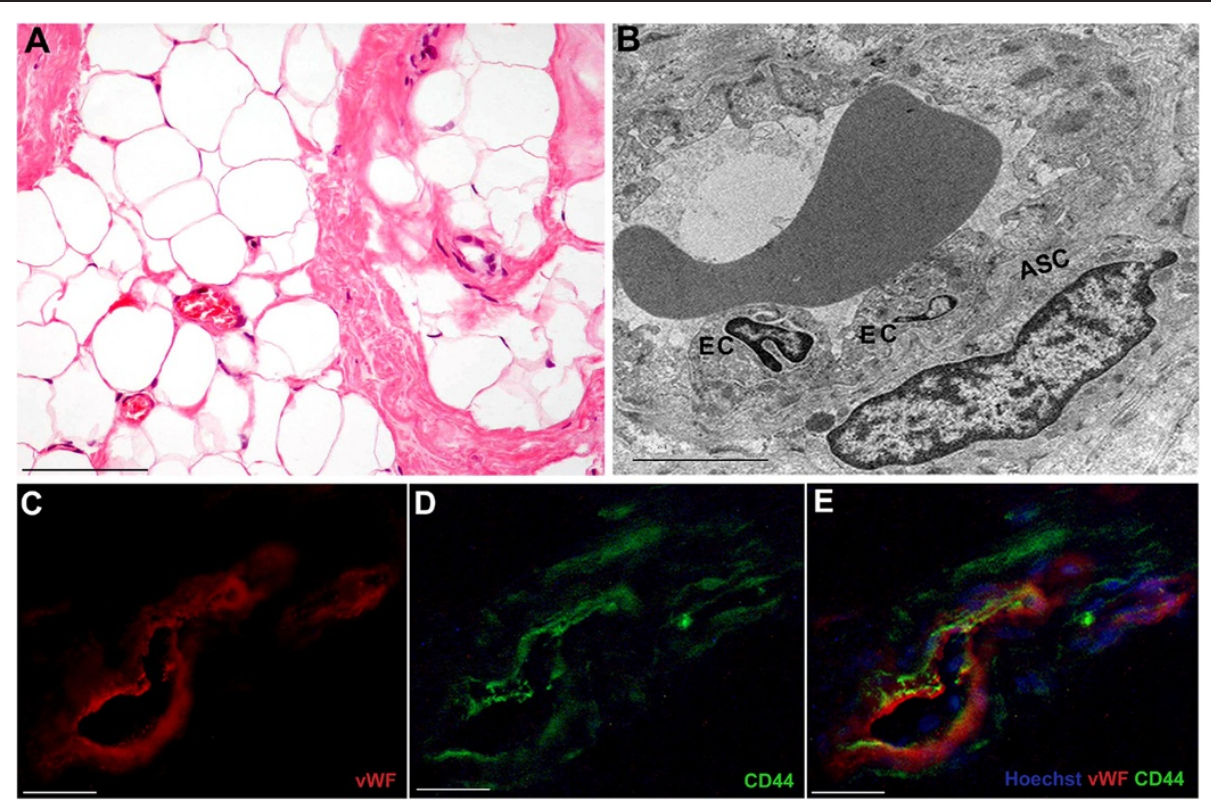

Figure 1 Microscopic characterization of human breast adipose tissue. A, Normal mammary adipose tissue after Haematoxylin and Eosin staining. Scale bar, $100 \mu \mathrm{m}$. B, transmission electron microscopy image of human breast adipose tissue showing perivascular adipose-derived stem cells (ASC) surrounding a small blood vessel with endothelial cells (EC). Scale bar, $10 \mu \mathrm{m}$. C, Under fluorescence microscopy, vascular endothelial cells are vonWillenbrand positive (red fluorescence) in the breast adipose tissue, whereas $\mathbf{D}$, adipose-derived stem cell are CD44 positive (green fluorescence). E, Merged image shows that CD44 positive cells reside around endothelial cells of small blood vessels in breast adipose tissue. Nuclei are stained with Hoechst. Scale bar, $100 \mu \mathrm{m}$.

adult stem cells, the so-called mesenchymal stem cells (MSCs) (Izadpanah et al. 2006). ASCs and MSCs share the ability to differentiate along multiple lineage pathways, including vasculogenetic properties. Cells with stem phenotype and vasculogenetic capacities have been also identified in the circulatory system, in the vessel wall and in various extravascular sites (Grenier et al. 2007; Orlandi \& Bennett 2010). Furthermore, ASCs can easily differentiate in mature adipocytes, and adipogenic differentiation is greatly increased by combined treatment with insulin and platelet-derived growth factors, with an increased long-term maintenance of fat grafts (Cervelli et al. 2012). Autologous fat grafting with SVF enrichment for regenerative surgical purposes, in particular in the therapy of post-traumatic lower extremity ulcers, give promising results (Cervelli et al. 2011). Similarly, SVF enrichment allows fat graft maintenance, likely favoring vascularization and collagen synthesis activity (Gentile et al. 2012b). These findings suggest the innovative use of the SVF/ASC enrichment and growth factors also in the breast reconstruction to avoid the frequent complications of fat grafting, including fat necrosis, cyst formation and calcification (Gutowski 2009). Adipose tissue is extremely metabolically active, as documented by its capacity to secrete hormones, growth factors and cytokines by both mature adipocytes and ASCs (Fruhbeck et al. 2001; Kilroy et al. 2007). Similarly, the discovery of ASCs as main actors in the regulatory scenario of adipose tissue cell turn-over requires further attention for the potential interplay between resident, grafted ASCs and residual breast cancer cells or adjacent in situ lesions. This finding induced caution and suggested some concerns about the use of fat grafting with SVF/ASC enrichment in breast reconstruction following cancer surgery. In the present review, we tried to describe the biomolecular pathways regulating proliferation and differentiation of ASCs, in order to define potential implications of breast cancer cell biology and risks for their use in post-surgery breast cancer reconstruction.

\section{Phenotypic characterization of adipose-derived stem cells}

ASCs share with MSCs the differentiation potential along several mesenchymal lineages (Gimble et al. 2007) (Peng et al. 2008). Nevertheless, some characteristics of ASCs, in particular the maintenance of proliferating ability in culture, are even greater than those of MSCs (Xu et al. 2005). The surface antigen profile of ASCs isolated from human adipose tissue, changes in vitro as a function of time and/ or passage in culture (Mitchell et al. 2006). Table 1 summarizes the antigenic profile of ASCs. After two or more passages in vitro, ASC surface immunophenotype resembles that of MSCs, with a similarity greater than $90 \%$ (Gimble et al. 2007). Nevertheless, some differences in surface protein expression have been described. The presence of the glycoprotein CD34 on the surface of human 
Table 1 Antigen profile of adipose-derived stem cell

\begin{tabular}{ll}
\hline Antigen Category & Surface-positive Antigens \\
\hline Cytoplasmic receptor & CD44 (hyaluronate), CD71 (transferrin) \\
Cell adhesion molecules & CD9, CD29, CD49 days, CD54, CD105,CD166 \\
Extracellular matrix & CD90, CD146, collagen types I and II, \\
markers molecule & osteopontin, osteonectin \\
Stromal markers & CD29, CD44, CD73, CD90, CD166 \\
Cytoskeleton markers & $\begin{array}{l}\text { a-smooth muscle actin, vimentin, calponin*, } \\
\text { caldesmin* }\end{array}$ \\
Stem cell markers & CD34, ABCG2 \\
\hline
\end{tabular}

*After 7-days TGF- $\beta 1$ treatment.
ASCs is not reported in MSCs (Pittenger et al. 1999). Since CD34 is abundantly expressed in human ASCs, immunofluorescence makes possible to identify ASCs as $\mathrm{CD}_{3}{ }^{+}$cells and to differentiate them from circulating precursors (Pittenger et al. 1999), confirming in human adipose tissue the presence of $\mathrm{CD}_{3} 4^{+}$cells and the perivascular origin of ASCs (Figure 1C-E). Cytofluorimetry and immunofluorescence represent suitable methods to investigate ASCs phenotype in vitro (Figure 2). Besides mesenchymal markers, such as CD44 and CD90, ASCs display pericytic markers, such as CD140a, CD140b and smooth muscle markers, such as $\alpha$-smooth muscle actin (Traktuev et al. 2008).

\section{Adipose-derived stem cells and angiogenesis}

The fascinating differentiative pluripotency of ASCs and their ability to enhance vascularization (Bertolini et al.
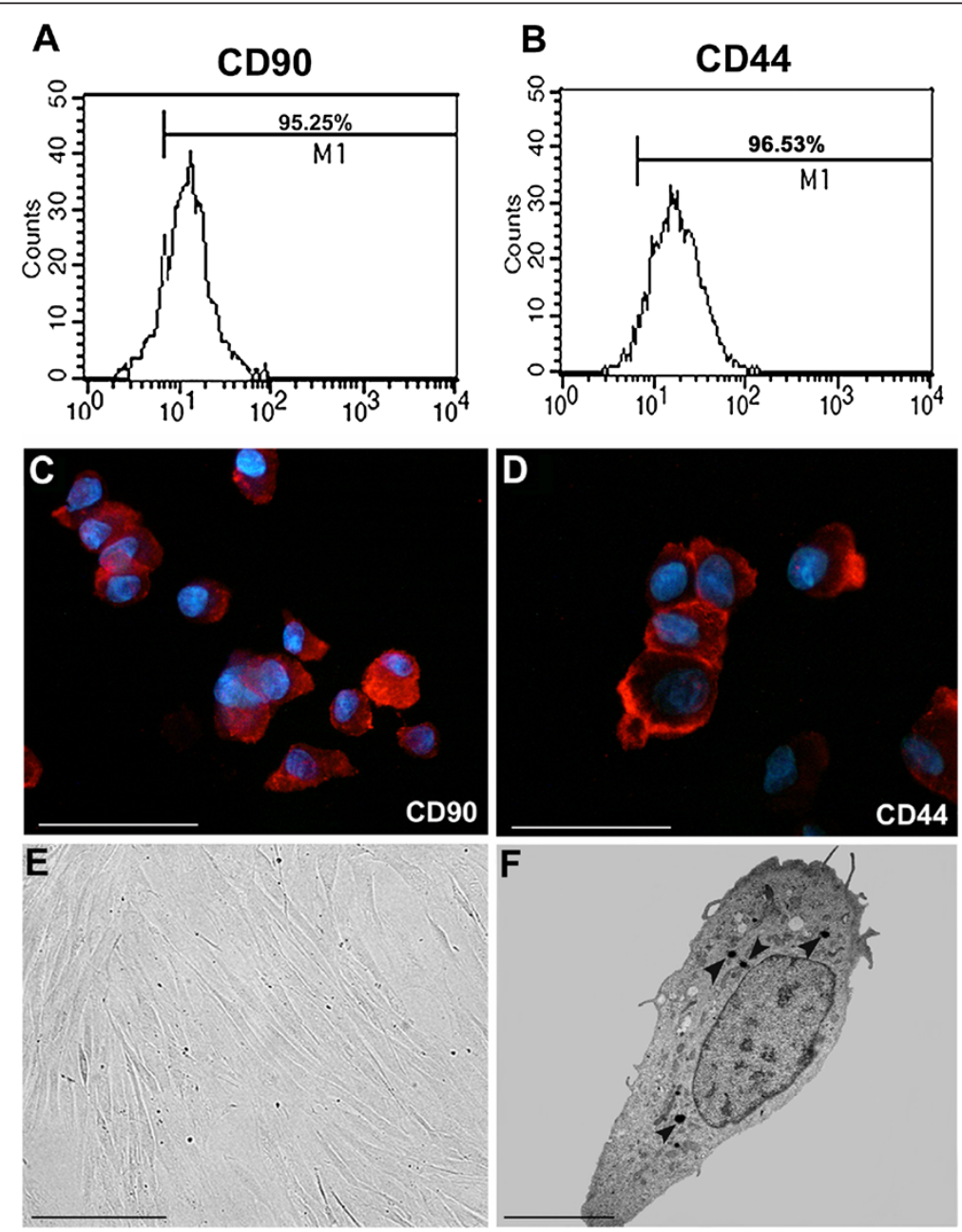

Figure 2 Phenotypic analysis of human adipose-derived stem cells. A and B, Flow cytometry depicting the diffuse expression of CD90 and CD44 stromal markers. $\mathbf{C}$ and $\mathbf{D}$, Immunofluorescence staining revealing the strong expression of CD44 and CD90 in cultured ASCs. Nuclei are stained with Hoechst. Scale bar, $50 \mu \mathrm{m}$ E, Phase contrast micrograph shows the typical elongated shape of adipose-derived stem cells in serum cultures. Scale bar, $150 \mu \mathrm{m} \mathbf{F}$, Transmission electron microscopy image showing adipose-derived stem cell with the presence of intracytoplasmic lipid droplet electron dense (arrow heads). Scale bar, $10 \mu \mathrm{m}$. 
2012; Merfeld-Clauss et al. 2010) progressively increased interest for their use in tissue engineering and regenerative medicine. The perivascular origin of ASCs and the expression of pericytic markers first suggested a role in vascular homeostasis of adipose tissue (Maumus et al. 2011). When transplanted, ASCs have the capacity to maintain the viability of fat transplanted through the secretion of growth factors that improve tissue survival (Kolle et al. 2013). Recent studies indicated that ASCs like MSCs are capable to promote angiogenesis through secretion of growth factors, in particular VEGF (Kinnaird et al. 2004; Salgado et al. 2010). Angiogenesis is a crucial event for cancer growth, and VEGF secretion plays a pivotal role in this process (Tarallo et al. 2010). Stem cells contribute to vascular remodelling by synthesizing collagen and secreting vascular growth factors (Orlandi and Bennett 2010). So, the expression of VEGF receptors in ASCs should be taken into account for future additional new anti-angiogenic strategies (Cassinelli et al. 2012) in breast cancer. It is worth of noting that ASCs share with resident vascular stem cells the paracrine production of VEGF (Cervelli et al. 2012; Ferlosio et al. 2012) and the expression of VEGF receptors (Kinnaird et al. 2004; Salgado et al. 2010). Furthermore, ASCs secrete hepatocyte growth factor, tumor necrosis factor- $\alpha$ and nerve growth factor (Salgado et al. 2010). Nerve growth factor and precursors are capable of inducing vascular remodeling by modulating vascular cells apoptotic sensitivity (Campagnolo et al. 2014).

\section{Cross-talk between mature adipocytes and breast cancer cells}

Many studies focused the relationship between mature adipocytes and breast cancer cells. Rat mature adipocytes affect the biological behavior of epithelial cells through the production of leptin, adiponectin, tumor necrosis factor- $\alpha$, heparin-binding epidermal growth factor, insulin-like growth factor-II and adipsin (Manabe et al. 2003). Furthermore, mature adipocytes metabolize androgen to estrogen trough their own aromatase activity (Miller et al. 1998). Estrogen synthesis affects breast carcinoma cell growth by a paracrine mechanism (Miller et al. 1998). Since breast adipose tissue is the major site of estrogen biosynthesis, its local delivering is likely involved in cancer progression. As matter of fact, estrogen level in breast tissues results 10 times greater than in blood as a consequence of high aromatase activity and tumor cells release stimulatory factors that amplify aromatase expression (Sasaki et al. 2010). Breast tumor cells also influence and modify the surrounding tissue microenvironment. Recent in vivo and in vitro studies demonstrated relevant phenotypic changes in adipocytes surrounding breast cancer (Dirat et al. 2011). Murine and human mature adipocytes co-cultured with tumor cells exhibited changes of the number and size of lipid droplets, a decrease of adipose markers level and over-expression of IL6, leading to a more aggressive tumor behavior (Walter et al. 2009). Also, mature adipocytes adjacent to the tumor showed a reduction of the expression of PPARY and lipid droplet accumulation (Chandler et al. 2012). Adipose tissue may also stimulate the growth and survival of breast tumor cells trough the secretion of adipokines, such as leptin and adiponectin (Bertolini et al. 2012). It appears evident that adipocytes surrounding breast cancer are subjected to significant transcriptional changes with a marked increased expression of endocrinerelated factors, influencing the growth and survival of breast cancer cells, in a paracrine loop (Ghosh et al. 2010). These findings support the hypothesis of an intimate cross-talk between breast cancer cells and immediately adjacent adipose tissue cells.

\section{Adipose-derived stem cells and breast cancer}

Differently from mature adipocytes, the interplay between resident mesenchymal cells, including ASCs, and breast epithelial cells is still partially unknown. In this respect, it is still unclear whether preadipocytes act differently from mature adipocytes. ASCs are located in perivascular niches and contribute to cell turn-over, vascular network for the maintenance of adipose tissue tropism (Strawford et al. 2004; Wang et al. 2012a) and to regulate stem cell homeostasis. Dynamic and reciprocal communication between epithelial and stromal compartments occurs during breast cancer progression, with the production and release of a large panel of cytokines, chemokines and growth factors which are essentials for the generation of a more favorable microenvironment for tumor growth (Dirat et al. 2011; Wiseman and Werb 2002). These signals are capable to induce the recruitment of several cells types including MSCs, so promoting cancer growth, metastasis and tumour stroma formation (Kucerova et al. 2013; Karnoub et al. 2007). Tumor microenvironment is heterogeneous and, in recent studies, the presence within tumor bulk of a cancer stem cell has been hypothesised. Cancer stem cells are defined as a subpopulation that constitute a small percentage of the tumor bulk and displayed analogies to normal stem cells, with both embryonic and adult aspects, supported by phenotypic (surface marker) and functional (metabolic enzymes and transporters) features and clonogenic potential (Donnenberg et al. 2013). In the primary tumor, cancer stem cell may arise from the transformation of resident stem cells or from dedifferentiation of differentiated tumor cells in response to specific microenvironmental signals (Park et al. 2014). The acquisition of cancer stem cell features may be a partial reminiscence of an embryonic phenotype with an increase of susceptibility to epithelialmesenchymal transition, supporting greater tumor growth 
and invasiveness (Park et al. 2014). Cells shift from a epithelial-like to a spindle-like morphology, accompanied by the expression of CD44 and CD90 stem markers and the maintenance of an adult stem cell phenotype (Donnenberg et al. 2013; Park et al. 2014). Furthermore, epithelial breast cancer cells undergoing to epithelialmesenchymal-transition showed mesenchymal features with loss of polarity and stem like spindle shape, that favor motility, invasiveness and survival (Hass \& Otte 2012). In this context, ASCs may interact with breast cancer cells through the formation of gap junctions that allows intercellular communication and the exchange of low molecular weight compounds (Donahue et al. 2003). The presence of gap junctions correlate with a more malignant phenotype and greater tumor progression and they can modulate the metastatic potential of the breast cancer cells (Mandel et al. 2013). Thus, the inhibition of gap junctions could partially block the stem cell-mediated growth induction and CD90 expression in breast cells. Conflicting data are reported concerning the role of ASCs in cancer progression. As reported, ASCs express surface markers, such as CD44, able to anchor some matrix-metalloproteinases to the cell surface. This CD44matrix-metalloproteinases association mediates the reorganization of extracellular matrix components (Hass and Otte 2012). Moreover, experiments in vivo and in vitro reported that ASCs favor tumor growth, increasing extracellular matrix deposition and vascularization, suggesting that ASCs may directly contribute to the dense network of fibroblasts and desmoplastic reaction surrounding breast cancer (Wang et al. 2012a). The desmoplastic reaction represents the stromal response to cancer cell infiltration and it is due to the disruption of the basement membrane and the inflammatory remodeling of the extracellular matrix (Pinilla et al. 2009). Desmoplastic reaction involves increased activity of tissue metalloproteinases and studies in vitro documented that co-culture of human ASCs and breast cancer cells induce high levels of metalloproteinases (Pinilla et al. 2009). Desmoplastic reaction also promotes myofibroblasts recruitment (De Wever et al. 2008; Karagiannis et al. 2012) and a large number of myofibroblasts are documented in the stromal compartment of invasive human breast cancers (Gehmert et al. 2010; Orimo et al. 2005). Myofibroblasts are stromal fibroblasts with both myocyte and fibroblast features (Orlandi et al. 1994). ASCs isolated from tumors also express high levels of alpha-smooth muscle actin, a well-known myofibroblastic marker (Tomasek et al. 2002). This suggests that ASCs could act as a potential source of tumor myofibroblasts.

To better clarify their role in cancer progression, studies in vivo and in vitro have been performed to verify ASCs influence on dormant tumor cells and on their growth and invasiveness. In literature is not yet clear whether dormant tumor cells are out of cell cycle, or persist in a dynamic state of proliferation and death. The transition between dormant and active states requires the presence of various signals, such as cytokines, hormones and growth factors (Donnenberg et al. 2010). Xenograft model experiments documented that grafted ASCs act in a different manner on active and dormant breast cancer cells. In fact, whereas the active cancer cells require growth factors and a new vascular network for the survival and invasiveness, the dormant cancer cells do not immediately require support of these factors. The latter are more autonomous and their growth is slower (Donnenberg et al. 2010; Zimmerlin et al. 2011). Consequently, these results indicate that grafted ASCs favour the growth of active, but not dormant, breast cancer cells. Moreover, ASCs transplantation or co-injected into mouse breast cancer model did not promote tumor growth or metastasis, and this inhibitory effect has been identified as the cause for ASC-dependent Poly ADP ribose polymerase cleavage, so inducing tumor cell apoptosis (Sun et al. 2009).

Altogether, these studies highlight the concept that resident ASCs and cancer cells may interact in a complex and dynamic fashion influencing the tumor behavior. Further studies are needed to better clarify this in vivo interaction and define how selectively stimulate ASCs regenerative function without influencing tumorigenesis.

\section{Similarities of growth and differentiative pathways of adipose-derived stem cells and breast cancer cells}

The proliferative arrest and/or cell loss are potential limitations in regenerative surgery strategies. So, exogenous growth factors should provide the necessary microenvironmental signals to accelerate cell proliferation, extracellular matrix synthesis and tissue deposition (Chen et al. 2010). Various receptor pathways regulated ASC proliferation and differentiation. Epidermal growth factor receptors (EGFRs), fibroblast growth factor receptors (FGFRs) and ErbB tyrosine kinase receptor (ErbB) families are involved in growth control and differentiation of cancer stem cells (Flageng et al. 2013; Nguyen et al. 2013; Reed et al. 2012; Liu et al. 2009). Recent studies documented the presence of EGFR and ErbB2 transcripts and proteins in ASCs (Cervelli et al. 2012). Platelet-derived growth factors stimulated ASCs proliferation and improved the maintenance of breast fat grafting in patients affected by soft tissue defects (Cervelli et al. 2012), but did not affect adipogenic differentiation of ASCs in vitro (Cervelli et al. 2009). This suggests that the pathways regulating proliferation and differentiation of ASCs are partially distinct. Plateletderived growth factors clinically ameliorated efficacy of fat grafting, likely favoring ASC proliferation (Cervelli et al. 2009). Insulin further increase long-term fat graft 
maintenance and greatly promoted adipogenic differentiation by increasing Akt activity and down-regulating the expression and activity of EGFR and ErbB2 receptors, without significant proliferative arrest of ASCs (Cervelli et al. 2012). Adipogenic differentiation also associated to the increased FGFR-2 and FGFR-1 transcript levels, suggests a complex receptor-mediated control of adipogenesis in ASCs (Cervelli et al. 2012). Although the clinical use of growth factors may improve long-term fat graft volume maintenance, growth factors may also influence the activity of resting cancer cells (Liu et al. 2009). As reported above, estrogen sustains growth in breast cancer through the transcriptional up-regulation of various growth factors, such as EGFR, and Akt phosphorylation (Liu et al. 2009). Moreover, a cross-talk between erbB and estrogen receptor-mediated signaling has been reported in tumor progression and resistance to endocrine therapy of breast cancer cells (Normanno et al. 2005). In addition, aberrant expression and activation of FGFR activity is involved in the progression of breast cancer (Grose et al. 2007). In particular, FGFR1 expression is associated with an early relapse and poor survival of breast cancer patients (Turner et al. 2010). In vitro data alone seem to suggest the caution in the local use of growth factors in addition to fat graft and further investigation of the interplay between ASCs and breast cancer cells should be performed also in vivo.

\section{Breast lipografting: clinical studies and follow-up}

Autologous fat grafting is a procedure widely used in breast reconstruction after cancer surgical treatment (Gentile et al. 2012b; Coleman and Saboeiro 2007). Clinical trials documented the absence of significant differences between patients undergoing lipofilling after mastectomy compared to untreated group. To minimize adverse effects, many attempts have been made to improve long term fat graft maintenance. A recent series of cases of breast reconstruction performed using autologous fat graft documented that, after a 10 years follow-up, there is no increased risk of relapse or new cancer development (Delay et al. 2009). In another study, 321 patients after breast cancer surgery treatment were subjected to lipofilling treatment (Petit et al. 2012). After six month, patients with lipofilling showed no relapse compared to untreated group. Nevertheless, when the study focused on patients previously diagnosed with breast intraepithelial neoplasia, the lipofilling group displayed a slightly higher risk of local recurrence, although not statistically significant, compared to the untreated group (Petit et al. 2012). However, a similar study carried out on 158 patients subjected to fat grafting procedures after a history of breast cancer surgery, did not show any increase risk of relapse after 18 month of follow-up (Rietjens et al. 2011). Other works compare the local recurrence before and after lipotransfer in patients undergoing mastectomy, with no statically significant differences between groups (Rigotti et al. 2010). Preliminary data from a relatively small number of patients describe that SVF enrichment improves fat graft survival, with no evidence of breast malignant transformation (Kolle et al. 2013). A recently introduced new technique combine the use of autologous SVF enrichment with platelet-derived growth factors to improve fat grafting maintenance after breast reconstruction. A series of 23 patients with breast cancer undergoing post-surgical breast reconstruction with fat grafting-SVF and plateletderived growth factors did not show increased risk of new cancer development after 1 year follow-up compared with the control group, but evidenced the ameliorated maintenance of breast volume (Cervelli et al. 2012). Although preliminary, these results seem to support that the addition of platelet-derived growth factors to lipografting induces a safe improvement of breast volume maintenance (Gentile et al. 2013), likely for the ability of platelet-derived growth factors to stimulate vascularization (Coleman and Saboeiro 2007; Gentile et al. 2013). Clinical studies with more patients and a longer follow-up are needed to confirm the safety of SVF/ASCs enrichment during fat grafting procedures with or without platelet-derived growth factors and hormones in breast cancer patients.

\section{New stem cell therapies and surgical breast cancer reconstruction}

Conventional cancer therapies include surgery, chemotherapy and radiotherapy. A certain number of preclinical studies recently proposed the use of MSCs as candidates to deliver anti-cancer drugs. Chemokines secreted by breast tumor cells are capable of stimulating MSCs migration and recruitment, suggesting a potential role for MSCs as delivery agents for chemotherapeutic purposes in breast tumours in vivo. MSCs can be readily transduced via adenoviral, retroviral or lentiviral vectors without compromising the capability for differentiation or the expression of surface markers. Consequently, MSCs are potentially suitable for a gene approach in cancer therapy through the induction of a more chronic and slow release of drugs that are often limited by their toxicity or short life (Kucerova et al. 2008). Interferon- $\beta$ is a powerful inhibitor of tumor cell growth, but to be efficacy it needs a dose higher than the maximally tolerated. In vitro, MSCs transduced with adenoviral vector carrying human Interferon- $\beta$ and co-cultured with breast cancer cells induced the reduction of cancer cells growth (Studeny et al. 2004). The same effect occurred, in vivo, when Interferon- $\beta$-transfected MSC cells are injected intravenously in a xenograft breast cancer mouse model (Studeny et al. 2004). The most of gene approaches use cytosine deaminase/5-fluorocytosine and thymidine 
kinase/ganciclovir. Ganciclovir is an inhibitor of DNA polymerase and, after DNA incorporation, inhibits chain elongation (Matuskova et al. 2012). The combined use of yeast cytosine deaminase gene with 5fluorocytosine allows the activation of 5-fluorouracile, a drug normally used in conventional chemotherapy (Matuskova et al. 2012). However, when ASCs are transduced with thymidine kinase/ganciclovir the growth of breast cancer cells was inhibited, but the latters have proved resistant to cytosine deaminase/5-fluorocytosine treatment. These opposite effects are linked to the capability of adult stem cells and tumor cells to communicate via gap junctions, determining both chemosensitivity than chemoresistance (Matuskova et al. 2012; Kucerova et al. 2012). In other works ASCs has been tested as vehicle to deliver tumor necrosis factor- $\alpha$ and to induce TRAILmediated apoptosis of cancer cells (Grisendi et al. 2010). TRAIL is a member of the tumor necrosis factor super-family that induces a selective apoptosis through the activation of death receptors in cancer target cells, with no relevant effects on healthy cells (Grisendi et al. 2010). More recently, PPAR ligands were shown capable of stimulating the differentiation of several cancer cells types, including breast cancer cells lines, suggesting a therapeutic utility in breast cancer treatment. PPAR $\gamma$ ligands inhibit the expression of aromatase and hence estrogen biosynthesis in adipose tissue surrounding human breast cancer (Rubin et al. 2000). At present, most hormonal therapies for breast cancer aim to the inhibit estrogen receptor and/or aromatase activity of cancer cells (den Hollander et al. 2013). Tamoxifen is an antagonist of estrogen receptor widely used in therapy of breast cancer, but after several years of treatment clonal cell line tumors become unresponsive to the drug (Higgins and Stearns 2009). The mechanism that underly tamoxifen resistance is still unclear. It's possible that the presence of cancer stem cell confers a drugs resistance. In vitro studies documented that cancer stem cell exert antiapoptotic effect on breast cancer cells and counteract cell-cycle changes caused by tamoxifen, so promoting tumor growth and invasiveness (Wang et al. 2012b; Lin et al. 2013).

Aromatase inhibitors are used as second-line therapy or as first-line adjuvant therapy, but they have the disadvantage to inhibit indiscriminately aromatases, including those in bone and brain tissues, with adverse effects in terms of bone mineralization and cognitive function, respectively (Rubin et al. 2000). An ideal goal is to develop a tissue-selective aromatase inhibitor. In these sense, ASCs potentially retain many of the attributes for an optimal cellular vehicle (Rubin et al. 2000). Additional studies need to document efficacy and safety of engineered ASCs before their application in clinical trials.

\section{Conclusions}

Current evidence sustains that ASCs represent a promising tool for innovative therapies in regenerative surgery and play a significant role in lipofilling-mediated breast reconstruction after breast cancer surgery. SVF/ ASCs enrichment seems to favor long-term fat graft maintenance in reconstruction of tissue defects, likely promoting vascularization and collagen synthesis. Preliminary studies in vivo seem to confirm the efficacy of SVF/ASCs enrichment and the beneficial additional use of autologous platelet-derived growth factors and hormones in breast reconstruction. The improvement in long-term maintenance strongly supports the additional combined use of fat grafts with autologous plateletderived growth factors and hormones, such as insulin. However, additional translational research studies are needed to better clarify the possible impact of these procedures on tumor microenvironment, in particular their potential effect on cancer cells. Different studies confirmed the complex and dynamic interplay between cancer cells and resident ASCs. Latters, in the tumor microenvironment, seem to affect only active cancer cells, so promoting neoangiogenesis, matrix remodeling and intercellular communication via gap-junction. In addiction, it has been hypothesized the presence of cancer stem cells, from resident stem cell or dedifferentiated tumor cells, that may favour the epithelial-mesenchymal transition, supporting tumor growth and invasiveness. In addition, the interaction between grafted ASCs and resting cancer cells doesn't seem to be responsible for cancer recurrence because resting cancer cells are more resistant to apoptosis and they don't require stroma or vascular structure for their survival. Preliminary data describe that SVF/ASCs enrichment did not show increased risk of new cancer or relapse compared with control group.

Finally, ASCs characteristics appear promising for their engineered use as "carrier" of adjuvant chemotherapeutic agents against residual breast cancer cells. So, the growth of malignant cells may be counteracted by local release of drugs in tumor microenvironment while systemic plasma concentration remain low, avoiding the problems related to toxicity and short life.

\section{Competing interests}

The authors declare that they have no competing interest.

\section{Authors' contribution}

$A B, M G S, A O$ : conception and design;PG, VC: collection and assembly of data; SA, CT: data analysis and interpretation; AO: writing and final approvation of the manuscript. All authors read and approved the manuscript.

\section{Acknowledgments}

We thank Dr Sabrina Cappelli, Dr Antonio Volpe for the technical work.

\section{Author details}

${ }^{1}$ Anatomic Pathology, Tor Vergata University of Rome, Via Montpellier, 00133 Rome, Italy. ${ }^{2}$ Plastic Surgery, Department of Biomedicine and Prevention, Tor Vergata University, Rome, Italy. 
Received: 15 April 2014 Accepted: 11 June 2014

\section{Published: 8 July 2014}

\section{References}

Bertolini F, Lohsiriwat V, Petit JY, Kolonin MG (2012) Adipose tissue cells, lipotransfer and cancer: a challenge for scientists, oncologists and surgeons. Biochim Biophys Acta 1826:209-214

Campagnolo L, Costanza G, Francesconi A, Arcuri G, Moscatelli I, Orlandi A (2014) Sortilin expression is essential for pro-nerve growth factor-induced apoptosis of rat vascular smooth muscle cells. PLoS One 9:e84969

Cassinelli G, Zuco V, Petrangolini G, De Cesare M, Tortoreto M, Lanzi C, Cominetti D, Zaffaroni N, Orlandi A, Passeri D, Meco D, Di Francesco AM, Riccardi R, Bucci F, Pisano C, Zunino F (2012) The curative efficacy of namitecan (ST1968) in preclinical models of pediatric sarcoma is associated with antiangiogenic effects. Biochem Pharmacol 84:163-171

Cervelli V, Gentile P, Scioli MG, Grimaldi M, Casciani CU, Spagnoli LG, Orlandi A (2009) Application of platelet-rich plasma in plastic surgery: clinical and in vitro evaluation. Tissue engineering Part C, Methods 15:625-634

Cervelli V, Gentile P, De Angelis B, Calabrese C, Di Stefani A, Scioli MG, Curcio BC, Felici M, Orlandi A (2011) Application of enhanced stromal vascular fraction and fat grafting mixed with PRP in post-traumatic lower extremity ulcers. Stem Cell Res 6:103-111

Cervelli V, Scioli MG, Gentile P, Doldo E, Bonanno E, Spagnoli LG, Orlandi A (2012) Platelet-rich plasma greatly potentiates insulin-induced adipogenic differentiation of human adipose-derived stem cells through a serine/threonine kinase Akt-dependent mechanism and promotes clinical fat graft maintenance. Stem cells translational medicine 1:206-220

Chandler EM, Seo BR, Califano JP, Andresen Eguiluz RC, Lee JS, Yoon CJ, Tims DT, Wang JX, Cheng L, Mohanan S, Buckley MR, Cohen I, Nikitin AY, Williams RM, Gourdon D, Reinhart-King CA, Fischbach C (2012) Implanted adipose progenitor cells as physicochemical regulators of breast cancer. Proc Natl Acad Sci U S A 109(25):9786-9791

Chen FM, Zhang M, Wu ZF (2010) Toward delivery of multiple growth factors in tissue engineering. Biomaterials 31:6279-6308

Coleman SR, Saboeiro AP (2007) Fat grafting to the breast revisited: safety and efficacy. Plast Reconstr Surg 119:775-785, discussion 786-777

Crisan M, Yap S, Casteilla L, Chen CW, Corselli M, Park TS, Andriolo G, Sun B, Zheng B, Zhang L, Norotte C, Teng PN, Traas J, Schugar R, Deasy BM, Badylak S, Buhring HJ, Giacobino JP, Lazzari L, Huard J, Péault B (2008) A perivascular origin for mesenchymal stem cells in multiple human organs. Cell Stem Cell 3:301-313

De Wever O, Demetter P, Mareel M, Bracke M (2008) Stromal myofibroblasts are drivers of invasive cancer growth. International journal of cancer Journal international du cancer 123:2229-2238

Delay E, Garson S, Tousson G, Sinna R (2009) Fat injection to the breast: technique, results, and indications based on 880 procedures over 10 years. Aesthetic surgery journal/the American Society for Aesthetic Plastic surgery 29:360-376

den Hollander P, Savage MI, Brown PH (2013) Targeted Therapy for Breast Cancer Prevention. Frontiers in oncology 3:250

Dirat B, Bochet L, Dabek M, Daviaud D, Dauvillier S, Majed B, Wang YY, Meulle A, Salles B, Le Gonidec S, Garrido I, Escourrou G, Valet P, Muller C (2011) Cancerassociated adipocytes exhibit an activated phenotype and contribute to breast cancer invasion. Cancer Res 71:2455-2465

Donahue HJ, Saunders MM, Li Z, Mastro AM, Gay CV, Welch DR (2003) A potential role for gap junctions in breast cancer metastasis to bone. J Musculoskelet Neuronal Interact 3:156-161

Donnenberg VS, Zimmerlin L, Rubin JP, Donnenberg AD (2010) Regenerative therapy after cancer: what are the risks? Tissue Eng Part B Rev 16:567-575

Donnenberg AD, Hicks JB, Wigler M, Donnenberg VS (2013) The cancer stem cell: cell type or cell state? Cytometry A 83:5-7

Ferlosio A, Arcuri G, Doldo E, Scioli MG, De Falco S, Spagnoli LG, Orlandi A (2012) Age-related increase of stem marker expression influences vascular smooth muscle cell properties. Atherosclerosis 224:51-57

Flageng MH, Knappskog S, Haynes BP, Lonning PE, Mellgren G (2013) Inverse regulation of EGFR/HER1 and HER2-4 in normal and malignant human breast tissue. PLoS One 8:e74618

Fruhbeck G, Gomez-Ambrosi J, Muruzabal FJ, Burrell MA (2001) The adipocyte: a model for integration of endocrine and metabolic signaling in energy metabolism regulation. Am J Physiol Endocrinol Metab 280:E827-E847
Gehmert S, Gehmert S, Prantl L, Vykoukal J, Alt E, Song YH (2010) Breast cancer cells attract the migration of adipose tissue-derived stem cells via the PDGF-BB/PDGFR-beta signaling pathway. Biochem Biophys Res Commun 398:601-605

Gentile P, Orlandi A, Scioli MG, Di Pasquali C, Bocchini I, Cervelli V (2012a) Concise review: adipose-derived stromal vascular fraction cells and plateletrich plasma: basic and clinical implications for tissue engineering therapies in regenerative surgery. Stem cells translational medicine 1:230-236

Gentile P, Orlandi A, Scioli MG, Di Pasquali C, Bocchini I, Curcio CB, Floris M, Fiaschetti V, Floris R, Cervelli V (2012b) A comparative translational study: the combined use of enhanced stromal vascular fraction and platelet-rich plasma improves fat grafting maintenance in breast reconstruction. Stem cells translational medicine 1:341-351

Gentile P, Di Pasquali C, Bocchini I, Floris M, Eleonora T, Fiaschetti V, Floris R, Cervelli V (2013) Breast reconstruction with autologous fat graft mixed with platelet-rich plasma. Surg Innov 20:370-376

Ghosh S, Dean A, Walter M, Bao Y, Hu Y, Ruan J, Li R (2010) Cell densitydependent transcriptional activation of endocrine-related genes in human adipose tissue-derived stem cells. Exp Cell Res 316:2087-2098

Gimble JM, Katz AJ, Bunnell BA (2007) Adipose-derived stem cells for regenerative medicine. Circ Res 100:1249-1260

Grenier G, Scime A, Le Grand F, Asakura A, Perez-Iratxeta C, Andrade-Navarro MA, Labosky PA, Rudnicki MA (2007) Resident endothelial precursors in muscle, adipose, and dermis contribute to postnatal vasculogenesis. Stem Cells 25:3101-3110

Grisendi G, Bussolari R, Cafarelli L, Petak I, Rasini V, Veronesi E, Spano C, Tagliazzucchi M, Barti-Juhasz H, Scarabelli L, Bambi F, Frassoldati A, Rossi G, Casali C, Morandi U, Horwitz EM (2010) Adipose-derived mesenchymal stem cells as stable source of tumor necrosis factor-related apoptosis-inducing ligand delivery for cancer therapy. Cancer Res 70:3718-3729

Grose R, Fantl V, Werner S, Chioni AM, Jarosz M, Rudling R, Cross B, Hart IR, Dickson C (2007) The role of fibroblast growth factor receptor $2 b$ in skin homeostasis and cancer development. The EMBO journal 26:1268-1278

Gutowski KA (2009) Current applications and safety of autologous fat grafts: a report of the ASPS fat graft task force. Plast Reconstr Surg 124:272-280

Hass R, Otte A (2012) Mesenchymal stem cells as all-round supporters in a normal and neoplastic microenvironment. Cell Commun Signal 10:26

Higgins MJ, Stearns V (2009) Understanding resistance to tamoxifen in hormone receptor-positive breast cancer. Clin Chem 55:1453-1455

Izadpanah R, Trygg C, Patel B, Kriedt C, Dufour J, Gimble JM, Bunnell BA (2006) Biologic properties of mesenchymal stem cells derived from bone marrow and adipose tissue. J Cell Biochem 99:1285-1297

Karagiannis GS, Poutahidis T, Erdman SE, Kirsch R, Riddell RH, Diamandis EP (2012) Cancer-associated fibroblasts drive the progression of metastasis through both paracrine and mechanical pressure on cancer tissue. Mol Cancer Res 10:1403-1418

Karnoub AE, Dash AB, Vo AP, Sullivan A, Brooks MW, Bell GW, Richardson AL, Polyak K, Tubo R, Weinberg RA (2007) Mesenchymal stem cells within tumour stroma promote breast cancer metastasis. Nature 449:557-563

Kilroy GE, Foster SJ, WU X, Ruiz J, Sherwood S, Heifetz A, Ludlow JW, Stricker DM, Potiny S, Green P, Halvorsen YD, Cheatham B, Storms RW, Gimble JM (2007) Cytokine profile of human adipose-derived stem cells: expression of angiogenic, hematopoietic, and pro-inflammatory factors. J Cell Physiol 212:702-709

Kinnaird T, Stabile E, Burnett MS, Lee CW, Barr S, Fuchs S, Epstein SE (2004) Marrow-derived stromal cells express genes encoding a broad spectrum of arteriogenic cytokines and promote in vitro and in vivo arteriogenesis through paracrine mechanisms. Circ Res 94:678-685

Kolle SF, Fischer-Nielsen A, Mathiasen AB, Elberg JJ, Oliveri RS, Glovinski PV, Kastrup J, Kirchhoff M, Rasmussen BS, Talman ML, Thomsen C, Dickmeiss E, Drzewiecki KT (2013) Enrichment of autologous fat grafts with ex-vivo expanded adipose tissue-derived stem cells for graft survival: a randomised placebo-controlled trial. Lancet 382(9898):1113-1120

Kucerova L, Matuskova M, Pastorakova A, Tyciakova S, Jakubikova J, Bohovic R, Altanerova V, Altaner C (2008) Cytosine deaminase expressing human mesenchymal stem cells mediated tumour regression in melanoma bearing mice. The journal of gene medicine 10:1071-1082

Kucerova L, Poturnajova M, Tyciakova S, Matuskova M (2012) Increased proliferation and chemosensitivity of human mesenchymal stromal cells expressing fusion yeast cytosine deaminase. Stem Cell Res 8:247-258

Kucerova L, Skolekova S, Matuskova M, Bohac M, Kozovska Z (2013) Altered features and increased chemosensitivity of human breast cancer cells 
mediated by adipose tissue-derived mesenchymal stromal cells. BMC Cancer 13:535

Lin X, Li J, Yin G, Zhao Q, Elias D, Lykkesfeldt AE, Stenvang J, Brünner N, Wang J, Yang H, Bolund L, Ditzel HJ (2013) Integrative analyses of gene expression and DNA methylation profiles in breast cancer cell line models of tamoxifenresistance indicate a potential role of cells with stem-like properties. Breast Cancer Res 15:R119

Liu B, Ordonez-Ercan D, Fan Z, Huang X, Edgerton SM, Yang X, Thor AD (2009) Estrogenic promotion of ErbB2 tyrosine kinase activity in mammary tumor cells requires activation of ErbB3 signaling. Mol Cancer Res 7:1882-1892

Manabe Y, Toda S, Miyazaki K, Sugihara H (2003) Mature adipocytes, but not preadipocytes, promote the growth of breast carcinoma cells in collagen gel matrix culture through cancer-stromal cell interactions. J Pathol 201:221-228

Mandel K, Yang Y, Schabach A, Glage S, Otte A, Hass R (2013) Mesenchymal stem cell directly interact with breast cancer cells and promote tumor cell growth in vitro and in vivo. Stem cell and development 22:3114-3127

Matuskova M, Baranovicova L, Kozovska Z, Durinikova E, Pastorakova A, Hunakova L, Waczulikova I, Nencka R, Kucerova L (2012) Intrinsic properties of tumour cells have a key impact on the bystander effect mediated by genetically engineered mesenchymal stromal cells. J Gene Med 14:776-787

Maumus M, Peyrafitte JA, D'Angelo R, Fournier-Wirth C, Bouloumie A, Casteilla L, Sengenès $C$, Bourin $P$ (2011) Native human adipose stromal cells: localization, morphology and phenotype. Int J Obes 35:1141-1153

Merfeld-Clauss S, Gollahalli N, March KL, Traktuev DO (2010) Adipose tissue progenitor cells directly interact with endothelial cells to induce vascular network formation. Tissue Eng A 16:2953-2966

Miller WR, Mullen P, Telford J, Dixon JM (1998) Clinical importance of intratumoral aromatase. Breast Cancer Res Treat 49(Suppl 1):S27-S32, discussion S33-27

Mitchell JB, McIntosh K, Zvonic S, Garrett S, Floyd ZE, Kloster A, Di Halvorsen Y, Storms RW, Goh B, Kilroy G, Wu X, Gimble JM (2006) Immunophenotype of human adipose-derived cells: temporal changes in stromal-associated and stem cell-associated markers. Stem Cells 24:376-385

Nguyen PT, Tsunematsu T, Yanagisawa S, Kudo Y, Miyauchi M, Kamata N, Takata T (2013) The FGFR1 inhibitor PD173074 induces mesenchymal-epithelial transition through the transcription factor AP-1. Br J Cancer 109:2248-2258

Normanno N, Di Maio M, De Maio E, De Luca A, de Matteis A, Giordano A, Perrone F, NCl-Naple Breast Cancer Group (2005) Mechanisms of endocrine resistance and novel therapeutic strategies in breast cancer. Endocrinerelated cancer 12:721-747

Orimo A, Gupta PB, Sgroi DC, Arenzana-Seisdedos F, Delaunay T, Naeem R, Carey VJ, Richardson AL, Weinberg RA (2005) Stromal fibroblasts present in invasive human breast carcinomas promote tumor growth and angiogenesis through elevated SDF-1/CXCL12 secretion. Cell 121:335-348

Orlandi A, Bennett M (2010) Progenitor cell-derived smooth muscle cells in vascular disease. Biochem Pharmacol 79:1706-1713

Orlandi A, Ehrlich HP, Ropraz P, Spagnoli LG, Gabbiani G (1994) Rat aortic smooth muscle cells isolated from different layers and at different times after endothelial denudation show distinct biological features in vitro. Arteriosclerosis and thrombosis: a journal of vascular biology/American Heart Association 14(6):982-989

Park TS, Donnenberg VS, Donnenberg AD, Zambidis ET, Zimmerlin L (2014) Dynamic interaction between cancer stem cells and their stromal patners. Curr Pathobiol Rep 2:42-52

Peng L, Jia Z, Yin X, Zhang X, Liu Y, Chen P, Ma K, Zhou C (2008) Comparative analysis of mesenchymal stem cells from bone marrow, cartilage, and adipose tissue. Stem Cells Dev 17:761-773

Petit JY, Botteri E, Lohsiriwat V, Rietjens M, De Lorenzi F, Garusi C, Rossetto F, Martella S, Manconi A, Bertolini F, Curigliano G, Veronesi P, Santillo B, Rotmensz N (2012) Locoregional recurrence risk after lipofilling in breast cancer patients. Annals of oncology:official journal of the European Society for Medical Oncology / ESMO 23:582-588

Pinilla S, Alt E, Abdul Khalek FJ, Jotzu C, Muehlberg F, Beckmann C, Song YH (2009) Tissue resident stem cells produce CCL5 under the influence of cancer cells and thereby promote breast cancer cell invasion. Cancer Lett 284:80-85

Pittenger MF, Mackay AM, Beck SC, Jaiswal RK, Douglas R, Mosca JD, Moorman MA, Simonetti DW, Craig S, Marshak DR (1999) Multilineage potential of adult human mesenchymal stem cells. Science 284:143-147

Reed JR, Stone MD, Beadnell TC, Ryu Y, Griffin TJ, Schwertfeger KL (2012) Fibroblast growth factor receptor 1 activation in mammary tumor cells promotes macrophage recruitment in a CX3CL1-dependent manner. PLoS One 7:e45877

Rietjens M, De Lorenzi F, Rossetto F, Brenelli F, Manconi A, Martella S, Intra M, Venturino M, Lhosiriwat V, Ahmed Y, Petit JY (2011) Safety of fat grafting in secondary breast reconstruction after cancer. Journal of plastic, reconstructive \& aesthetic surgery 64:477-483

Rigotti G, Marchi A, Stringhini P, Baroni G, Galie M, Molino AM, Mercanti A, Micciolo R, Sbarbati A (2010) Determining the oncological risk of autologous lipoaspirate grafting for post-mastectomy breast reconstruction. Aesthet Plast Surg 34:475-480

Rubin GL, Zhao Y, Kalus AM, Simpson ER (2000) Peroxisome proliferator-activated receptor gamma ligands inhibit estrogen biosynthesis in human breast adipose tissue: possible implications for breast cancer therapy. Cancer Res 60:1604-1608

Salgado AJ, Reis RL, Sousa NJ, Gimble JM (2010) Adipose tissue derived stem cells secretome: soluble factors and their roles in regenerative medicine. Current stem cell research \& therapy 5:103-110

Sasaki Y, Miki Y, Hirakawa H, Onodera Y, Takagi K, Akahira J, Honma S, Ishida T, Watanabe M, Sasano H, Suzuki T (2010) Immunolocalization of estrogen-producing and metabolizing enzymes in benign breast disease: comparison with normal breast and breast carcinoma. Cancer Sci 101:2286-2292

Strawford A, Antelo F, Christiansen M, Hellerstein MK (2004) Adipose tissue triglyceride turnover, de novo lipogenesis, and cell proliferation in humans measured with $2 \mathrm{H} 2 \mathrm{O}$. Am J Physiol Endocrinol Metab 286:E577-E588

Studeny M, Marini FC, Dembinski JL, Zompetta C, Cabreira-Hansen M, Bekele BN, Champlin RE, Andreeff M (2004) Mesenchymal stem cells: potential precursors for tumor stroma and targeted-delivery vehicles for anticancer agents. J Natl Cancer Inst 96:1593-1603

Sun B, Roh KH, Park JR, Lee SR, Park SB, Jung JW, Kang SK, Lee YS, Kang KS (2009) Therapeutic potential of mesenchymal stromal cells in a mouse breast cancer metastasis model. Cytotherapy 11:289-298, 281 p following 298

Tarallo V, Vesci L, Capasso O, Esposito MT, Riccioni T, Pastore L, Orlandi A, Pisano C, De Falco S (2010) A placental growth factor variant unable to recognize vascular endothelial growth factor (VEGF) receptor-1 inhibits VEGF-dependent tumor angiogenesis via heterodimerization. Cancer Res 70:1804-1813

Tomasek JJ, Gabbiani G, Hinz B, Chaponnier C, Brown RA (2002) Myofibroblasts and mechano-regulation of connective tissue remodelling. Nat Rev Mol Cell Biol 3:349-363

Traktuev DO, Merfeld-Clauss S, Li J, Kolonin M, Arap W, Pasqualini R, Johnstone $\mathrm{BH}$, March KL (2008) A population of multipotent CD34-positive adipose stromal cells share pericyte and mesenchymal surface markers, reside in a periendothelial location, and stabilize endothelial networks. Circ Res 102:77-85

Tran KV, Gealekman O, Frontini A, Zingaretti MC, Morroni M, Giordano A, Smorlesi A, Perugini J, De Matteis R, Sbarbati A, Corvera S, Cinti S (2012) The vascular endothelium of the adipose tissue gives rise to both white and brown fat cells. Cell Metab 15:222-229

Turner N, Pearson A, Sharpe R, Lambros M, Geyer F, Lopez-Garcia MA, Natrajan R, Marchio C, lorns E, Mackay A, Gillett C, Grigoriadis A, Tutt A, Reis-Filho JS, Ashworth A (2010) FGFR1 amplification drives endocrine therapy resistance and is a therapeutic target in breast cancer. Cancer Res 70:2085-2094

Walter M, Liang S, Ghosh S, Hornsby PJ, Li R (2009) Interleukin 6 secreted from adipose stromal cells promotes migration and invasion of breast cancer cells. Oncogene 28:2745-2755

Wang YY, Lehuede C, Laurent V, Dirat B, Dauvillier S, Bochet L, Le Gonidec S, Escourrou G, Valet P, Muller C (2012a) Adipose tissue and breast epithelial cells: a dangerous dynamic duo in breast cancer. Cancer Lett 324:142-151

Wang X, Wang G, Zhao Y, Liu X, Ding Q, Shi J, Ding Y, Wang S (2012b) STAT3 mediates resistance of CD44 (+) CD24 (-/low) breast cancer stem cells to tamoxifen in vitro. J Biomed Res 26:325-335

Wiseman BS, Werb Z (2002) Stromal effects on mammary gland development and breast cancer. Science 296:1046-1049

Xu Y, Malladi P, Wagner DR, Longaker MT (2005) Adipose-derived mesenchymal cells as a potential cell source for skeletal regeneration. Curr Opin Mol Ther 7:300-305

Zhao M, Dumur Cl, Holt SE, Beckman MJ, Elmore LW (2010) Multipotent adipose stromal cells and breast cancer development: think globally, act locally. Mol Carcinog 49:923-927 
Zimmerlin L, Donnenberg AD, Rubin JP, Basse P, Landreneau RJ, Donnenberg VS (2011) Regenerative therapy and cancer: in vitro and in vivo studies of the interaction between adipose-derived stem cells and breast cancer cells from clinical isolates. Tissue Eng A 17(1-2):93-106

Zuk PA, Zhu M, Mizuno H, Huang J, Futrell JW, Katz AJ, Benhaim P, Lorenz HP, Hedrick MH (2001) Multilineage cells from human adipose tissue: implications for cell-based therapies. Tissue Eng 7:211-228

doi:10.1186/2193-1801-3-345

Cite this article as: Bielli et al:: Adult adipose-derived stem cells and

breast cancer: a controversial relationship. SpringerPlus 2014 3:345.

\section{Submit your manuscript to a SpringerOpen ${ }^{\circ}$} journal and benefit from:

- Convenient online submission

- Rigorous peer review

- Immediate publication on acceptance

- Open access: articles freely available online

- High visibility within the field

- Retaining the copyright to your article

Submit your next manuscript at $\gg$ springeropen.com 